\title{
Studies in Informatics and Control: A Bibliometric Analysis from 2008 to 2019
}

\author{
Y. Li, Z.S. Xu, X.X. Wang, F.G. Filip
}

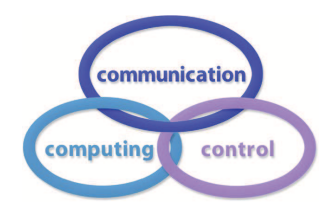

\section{Yang Li}

Business School

Sichuan University, China

No. 24, South section 1 of the first ring road, Chengdu, 610064, China liyang_ly18@163.com

\section{Zeshui $\mathrm{Xu}^{*}$}

Business School

Sichuan University, China

No. 24, South section 1 of the first ring road, Chengdu, 610064, China

*Corresponding author: xuzeshui@263.net

\author{
Xinxin Wang \\ Business School \\ Sichuan University, China \\ No. 24, South section 1 of the first ring road, Chengdu, 610064, China \\ wangxinxin_cd@163.com
}

\section{Florin Gheorghe Filip}

Romanian Academy

125 Calea Victoriei, Bucharest, 010071, Romania

ffilip@acad.ro

\begin{abstract}
As an international scientific journal, Studies in Informatics and Control (SIC) covers the field of Information Technology (IT) and topics related to research areas, as well as important applications in IT, with particular emphasis on Advanced Automatic Control, Modeling and Optimization. SIC has greatly contributed to the areas where it involves since its first online publication way back in 1992. This paper sets out to analyze the structure and the underlying trend of the journal by making use of bibliometric methods. Firstly, the classical indicators are provided to illustrate the performance of the journal. This current study performs an in-depth analysis of the most productive and the most influential authors, institutions, and countries/regions, as well as the most cited research works published in SIC. Secondly, the visualization tools VoS viewer and CiteSpace are used to create scientific maps that may explain the structure of the journal in an intuitionistic way. In the science mapping, the co-citation maps, and the co-authorship networks of various items (such as authors, institutions, and countries/regions) are conducted. Also, the bursts detection of these items are derived. The co-occurrence of keywords and their bursts detection and timeline review are shown, respectively. Finally, some conclusions are given. This paper provides a comprehensive and visual understanding of this well-regarded scientific journal.
\end{abstract}

Keywords: Studies in Informatics and Control, bibliometric analysis, science mapping analysis, Web of Science, information technology. 


\section{Introduction}

As an international scientific journal, Studies in Informatics and Control (SIC) is one of the leading journals in the field of Information and Communication Technologies (I\&CT) in Romania. It provides important perspectives on topics relevant to Information Technology (IT), with an emphasis on useful applications in the most important areas of IT such as Automatic Control, System Modeling and Optimization. The journal was first published in 1989 under the name "Studies in Computers and Informatics" as a publication of the Institute for Computer Technique and Informatics (ITCI). It was renamed as the current name $S I C$ in 1990. In 1992, the journal became an international one with an Editorial Board of scientists from 17 countries and prof. Theodore Williams of Purdue University played a major role in shaping journal profile. Since 1992, SIC has been published both in print and online by the Romanian Institute for R\&D in Informatics, ICI Burcharest under the auspices of the Romanian Academy [12]. According to the current homepage of the journal (https://sic.ici.ro/about-sic/), this quarterly journal has been included within the coverage of Inspec database (since 1993), DOAJ (since 1996), Google Scholar (since 2006) and Philadelphia-based Institute of Scientific Information (ISI Thomson-Reuters) / Clarivate Analytics - Science Citation Index Expanded (SCIE) (since 2008), Scopus (since 2010) and other relevant academic databases and search engines listings. The journal impact factor in 2018 was 1.347 according to the Journal Citation Reports (JCR) published in Web of Science (WoS). The ranking of the journal in the research field of automation \& control system was 45 out of 62 while in the field of operations research \& management science it was 53 out of 84 . Prof. F.G. Filip, a member of the Romanian Academy, is the founder and editor-in-chief of the journal.

Bibliometrics analyze patterns that appear in the publication and communication of documents by using mathematical and statistical methods [11]. It provides a systematic, transparent, and reproducible review to a large body of information by providing a structural analysis [1]. Bibliometric methods are used in various fields for the purpose of research evaluation [19]. Because bibliometrics is effective in revealing the evaluation of a research direction, it has been applied in many fields, such as economy [10], management [21], innovation [5,13], decision support [14] and entrepreneurship $[16,17]$. In addition, it also has been widely used to evaluate a certain journal, including European Journal of Operational Research [15], Information Sciences [29], IEEE Transaction on Fuzzy Systems [28], International Journal of Intelligent Systems [18], Knowledge-Based System [8], Technological and Economic Development of Economy [27], International Journal of Strategic Property Management [31], International Journal of Computers Communications \& Control [25], etc.

The bibliometric evaluation comprises two procedures [20]: performance analysis and science mapping. The performance analysis evaluates the performance of different scientific actors based on the number of publications and citations [8] and it is illustrated by a series of bibliometric indicators. The science mapping mostly aims at displaying the structure, evaluation and dynamic aspects of scientific research $[2,3]$. In fact, many visualization tools or softwares are created to make science mapping analysis, and Cobo et.al [7] made a comparation of them. Two of the most common science mapping softwares, VoS viewer and CiteSpace are applied in this paper. VoS viewer represents the bibliometric map in an easy-to-interpret way [24] and can construct the maps of co-citation, co-authorship, co-occurrence, citation and bibliographic coupling. Besides, burst-detection provided by CiteSpace helps scholars to identify emergent terms regardless of how many times their host documents are cited [6]. The hot topics and research trends can be detected from the time-line view of CiteSpace.

The main contribution of this paper consists in performing a bibliometric analysis of the research works published in SIC. The bibliomteric indicators are applied to various levels such 
as authors, institutions, and countries/regions. The analysis of co-citation, co-authorship and co-occurrence concerning various items, as well as the burst detection and time-line view are presented in science mapping. The rest of this paper is structured as follows: Section 2 describes the source of data used in this paper, and the performance analysis of SIC is illustrated in Section 3. In Section 4, scientific maps and relative evaluation are presented. Furthermore, some conclusions are given in Section 5.

\section{Data description}

According to the website of SIC (https://sic.ici.ro/), the journal has been included within the coverage of Clarivate Analytics - SCIE (since 2008). Clarivate Analytics is a company with an entrepreneurial mission to help customers reduce the time from new ideas to life-changing innovations. SCIE created as SCI in 1964 indexes more than 9,200 of the world's most impactful journals across 178 scientific disciplines. And it contains more than 53 million records and 1.18 billion cited references way back from 1900 to 2019. Since the SCIE is included in the WoS Core Collection, relative data have been downloaded from WoS Core Collection SCIE (https://apps.webofknowledge.com/) to analyze the performance of research works published in the journal from 2008 to November 1, 2019. With the database set at WoS Core Collection, the citation indexes set at SCIE and the timespan set at 2008-2019, full records and cited references of documents in $S I C$ are searched and exported in plain text form in November 1, 2019. The performance analysis and science mapping analysis of the journal are based on 527 papers that have been searched and their relative information derived from WoS.

\section{Performance analysis of $S I C$}

In this section, the annual publications and citations of the journal are described. Depending on the bibliometric indicators, the most productive and influential authors, countries/regions, and institutions are exhibited, as well as the most cited documents.

\subsection{Annual publications and citations}

Since 2008, 527 research works have been published in SIC, among which 517 documents are articles, which accounts for $98.102 \%$ of the total number of research works. The other four types of the documents are editorial materials $(6 ; 1.139 \%)$, proceeding papers $(6 ; 1.139 \%)$, reviews $(3$; $0.569 \%)$ and biographical items $(1 ; 0.19 \%)$.

It can be seen from Figure 1 that, the annual publications in $S I C$ are constant. The minimum number of publications was 38 in 2008 and 2014, and the maximum number of publications was 51 in 2016 and 2017. Since SIC was included within the coverage of Clarivate Analytics - SICE in 2008, the number of annual citations of this scientific journal keeps to increase rapidly and exceeded 50 in 2010 and 100 in 2012 for the first time. A great augment of citations appeared in 2018. The number of citations is 351 in 2018, which is 82 higher than that in 2017 (269 citations). During the past 10 months of 2019, the research works in SIC has been cited 312 times, which is higher than the number of citations in 2017.

In order to illustrate the citation structure of the publications in $S I C$, the relative information is listed in Table 1. The number of publications $(\mathrm{P})$, the number of citations $(\mathrm{C})$, the number of cumulative publications and citations $(\mathrm{CP}$ and $\mathrm{CC})$, the number of document whose number of citations is more than 50 ( $\geq 50), 30(\geq 30), 20(\geq 20), 10(\geq 10), 5(\geq 5)$ and $1(\geq 1)$, H-index (the abbreviation of Hirsch-index) [9] and the total citations of annual publications (TC) are listed by year to evaluate performance. 


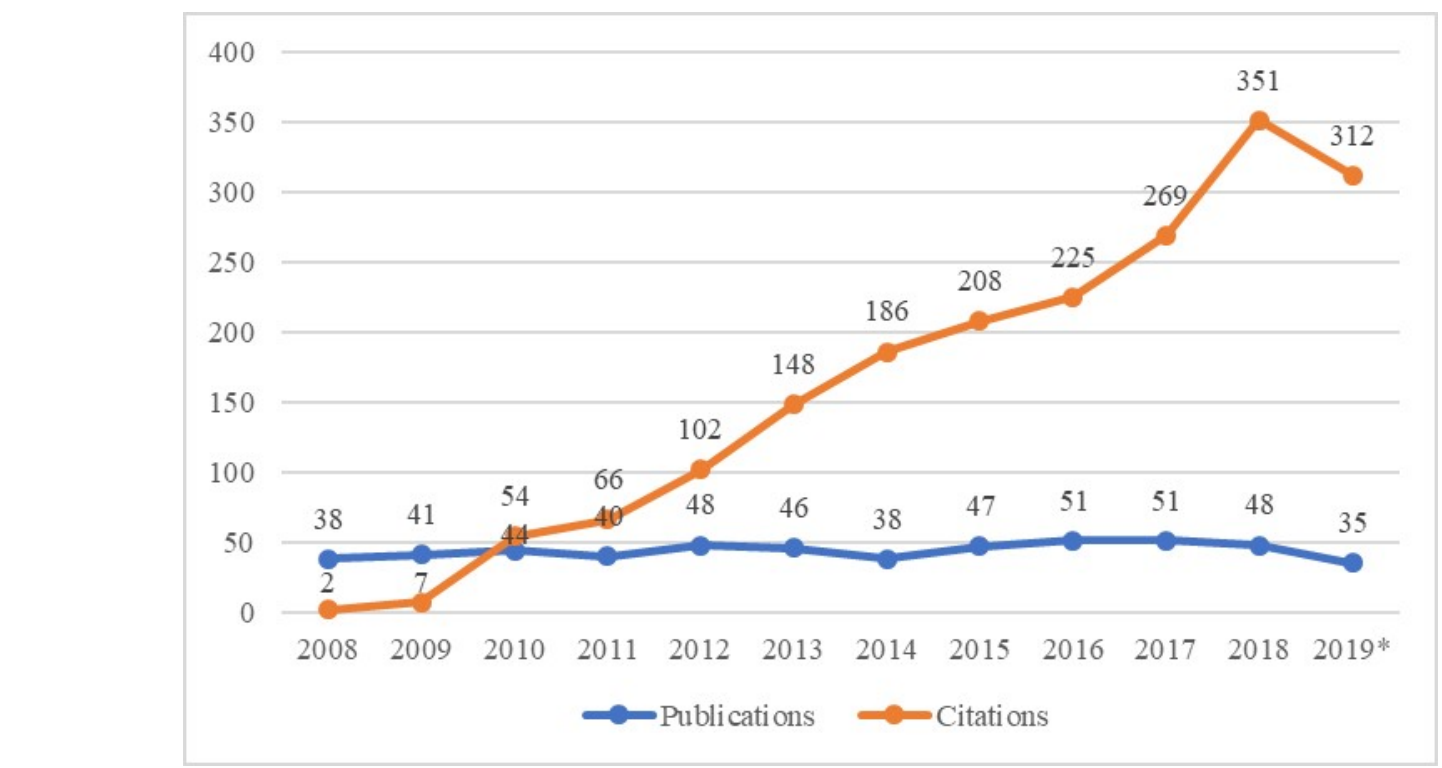

* As of November 1, 2019.

Figure 1: Annual publications and citations from 2008 to 2019*.

The number of $\mathrm{C}$ became greater than that of $\mathrm{P}$ in 2010 for the first time and the number of $\mathrm{CC}$ is higher than the number of CP since 2012. It means that all the publications in SIC have been cited at least once on average. During the 12-year period, only 2 documents published in 2012 and 2015 are cited not less than 50 times. 6 of 527 documents are cited not less than 30 times, and 2 of the 6 documents published in 2013. 14 of 527 documents are cited not less than 20 times, and 4 of the 14 documents published in SIC in 2010. The 44 documents published in 2010 gained much attention and made much influence with the highest number of citations (254). 4 of the 44 documents are cited not less than 20 times, 8 of the 44 documents are cited not less than 10 times, and the H-index of the 44 documents is 9 . These 3 indicators are the highest compared with them of other 11 years. The highest numbers of documents with number of citations not less than 30 and not less than 5 are in 2013. In the year of 2016, 44 of the 51 documents are cited at least once, which is the highest compared with other 11 years. Based on the above analysis, it can be found that the documents in 2010, 2012, 2013, 2015 and 2016 have greatly contributed to $S I C$.

\subsection{The most productive and influential authors and documents}

In this subsection, some bibliometric indicators concerning the publications and the citations are utilized to evaluate authors and documents.

\section{The most productive and the most influential authors}

Table 2 lists the top 8 productive authors who published not less than 10 articles in SIC since 2008. Some indicators such as $\mathrm{P}$, the year of first publication (YFP), the year of latest publication (YLP), average publications (AP) and type of their research works, are shown in Table 2.

Benrejeb, M. is the most productive author who has published 13 documents in the journal since 2008. Thorsteinsson, G. from Iceland published 12 articles in this journal from 2008 to 2016 and the AP of him is 1.33. Niculescu, A. from Romania published 11 articles and 1 editorial 
Table 1: Characteristics of annual publications from 2008 to $2019^{*}$.

\begin{tabular}{ccccccccccccc}
\hline Year & $\mathbf{P}$ & $\mathbf{C}$ & $\mathbf{C P}$ & $\mathbf{C C}$ & $\mathbf{2 5 0}$ & $\mathbf{2} \mathbf{3 0}$ & $\mathbf{2} \mathbf{2 0}$ & $\mathbf{\geq 1 0}$ & $\mathbf{\geq 5}$ & $\mathbf{\geq}$ & $\mathbf{H}$-index & $\mathbf{T C}$ \\
\hline 2008 & 38 & 2 & 38 & 2 & 0 & 0 & 0 & 4 & 7 & 30 & 6 & 113 \\
2009 & 41 & 7 & 79 & 9 & 0 & 0 & 1 & 3 & 10 & 35 & 6 & 147 \\
2010 & 44 & 54 & 123 & 63 & 0 & 0 & $\mathbf{4}$ & $\mathbf{8}$ & 16 & 37 & $\mathbf{9}$ & $\mathbf{2 5 4}$ \\
2011 & 40 & 66 & 163 & 129 & 0 & 1 & 1 & 2 & 11 & 37 & 6 & 162 \\
2012 & 48 & 102 & 211 & 231 & $\mathbf{1}$ & 1 & 1 & 6 & 14 & 41 & 8 & 239 \\
2013 & 46 & 148 & 257 & 379 & 0 & $\mathbf{2}$ & 2 & 7 & $\mathbf{1 7}$ & 39 & 8 & 247 \\
2014 & 38 & 186 & 295 & 565 & 0 & 0 & 2 & 2 & 8 & 32 & 6 & 131 \\
2015 & 47 & 208 & 342 & 773 & $\mathbf{1}$ & 1 & 1 & 4 & 10 & 39 & 5 & 192 \\
2016 & $\mathbf{5 1}$ & 225 & 393 & 998 & 0 & 0 & 0 & 2 & 10 & $\mathbf{4 4}$ & 5 & 141 \\
2017 & $\mathbf{5 1}$ & 269 & 444 & 1267 & 0 & 1 & 2 & 4 & 16 & 38 & 8 & 217 \\
2018 & 48 & $\mathbf{3 5 1}$ & 492 & 1618 & 0 & 0 & 0 & 3 & 4 & 22 & 4 & 82 \\
$2019 *$ & 35 & 312 & 527 & 1897 & 0 & 0 & 0 & 0 & 0 & 5 & 1 & 5 \\
* As of November 1, 2019
\end{tabular}

* As of November 1, 2019.

Table 2: The top 8 productive authors in $S I C$ from 2008 to 2019*.

\begin{tabular}{cccccccl}
\hline Rank & Authors & Countries & P & YFP & YLP & AP & \\
\hline 1 & Benrejeb, M & Tunisia & 13 & 2008 & 2018 & 1.18 & Article (13) \\
2 & Thorsteinsson, G & Iceland & 12 & 2008 & 2016 & 1.33 & Article (12) \\
3 & Niculescu, A & Romania & 12 & 2008 & 2019 & 1.00 & Article (11), Editorial material (1) \\
4 & Page, T & England & 11 & 2008 & 2013 & $\mathbf{1 . 8 3}$ & Article (11) \\
5 & Wang, H. P & China & 11 & 2010 & 2019 & 1.10 & Article (11) \\
6 & Tian, Y & China & 11 & 2014 & 2019 & $\mathbf{1 . 8 3}$ & Article (11) \\
7 & Borne, P & France & 10 & 2008 & 2019 & 0.83 & Article (10) \\
8 & Radulescu, C. Z & Romania & 10 & 2009 & 2019 & 0.91 & Article (10) \\
\hline
\end{tabular}

* As of November 1, 2019.

material in SIC since 2008 and he published 1 document in the journal per year on average. The 2 authors with highest number of AP (1.83) is Page, T. from England and Tian, Y. from China. Page, T published his 11 articles in SIC during the period from 2008 to 2013, while Tian, Y. published 11 articles in the journal in the last 6 years. In terms of YFP, 5 of the top 8 productive authors started to publish in the journal since 2008. 5 of the top 8 productive authors continue to publish in the journal until 2019. 2 of the top 8 productive authors come from Romania, and another 2 of the 8 authors are from China. The other 4 authors come from Tunisia, Iceland, England and France, respectively. The research areas of all these 8 authors are operations research \& management science and automation \& control systems, according to the classification of WoS.

According to some common indicators about citations, Table 3 lists the top 3 influential authors with the number of citations higher than 100 .

Table 3: The top 3 influential authors in SIC from 2008 to 2019*.

\begin{tabular}{ccccccccccccc}
\hline Rank & Authors & Country & P & C & AC & $\geq \mathbf{5 0}$ & $\geq \mathbf{3 0}$ & $\geq \mathbf{2 0}$ & $\geq \mathbf{1 0}$ & $\geq \mathbf{5}$ & $\geq \mathbf{1}$ & H-index \\
\hline 1 & Zavadskas, E. K & Lithuania & 8 & 170 & 21.25 & 1 & 2 & 3 & $\mathbf{5}$ & $\mathbf{7}$ & $\mathbf{7}$ & $\mathbf{7}$ \\
2 & Turskis, Z & Lithuania & 5 & 128 & $\mathbf{2 5 . 6}$ & 1 & 2 & 3 & 4 & 4 & 4 & 4 \\
3 & Tuba, M & Serbia & 7 & 115 & 16.43 & 1 & 2 & 3 & 4 & 4 & 6 & 4 \\
\hline
\end{tabular}

* As of November 1, 2019.

In Table 3, $\mathrm{P}$ and $\mathrm{C}$ are the publications and citations of the authors respectively, and 
AC represents the average citations of an author. Zavadskas, E. K. from Lithuania published 8 articles in SIC and obtained 170 citations in total. The $\mathrm{H}$-index of him is 7 , which means that there are 7 of his articles published in the journal cited at least 7 times. The AC of Turskis, Z. from Lithuania (25.6) is the highest, for he published only 5 articles in the journal and obtained 128 citations. All of the 3 authors have 1 article cited not less than 50 times and have 1 article has not been cited until November 1, 2019. There is some interesting information observed on the website of WoS. Only 2 articles in SIC are cited not less than 50 times, and 1 of them is a cooperative article published in June 2015 by Zavadskas, E.K, Turskis, Z. and Antucheviciene, J., while another one is the work of Bacanin, $\mathrm{N}$ and Tuba, M. The 2 articles written by the 3 authors with on citations are published in September 2019. 1 of the 2 articles is "A Novel Extended EDAS in Minkowski Space (EDAS-M) Method for Evaluating Autonomous Vehicles" [30] written by Zavadskas, E.K, Stevic, Z, Turskis, Z and Tomasevic, M. The another one is written by Tuba, M together with Tuba, E, namely article "Generative Adversarial Optimization (GOA) for Acute Lymphocytic Leukemia Detection" [23].

\section{The most cited documents}

To analyze the influence of the documents published in the journal during the period from 2008 to November 1, 2019, the top 6 cited publications which have been cited not less than 30 times, are listed in Table 4. The relative information, namely C, AC, the number of authors (NA), the type of document, the publication year, and research area (RA) of these publications are also listed.

Table 4: The top 6 influential documents in SIC from 2008 to $2019^{*}$.

\begin{tabular}{|c|c|c|c|c|c|c|c|c|}
\hline Rank & Title & Authors & $\mathrm{C}$ & $\mathrm{AC}$ & NA & Type & Year & RA \\
\hline 1 & $\begin{array}{l}\text { Selecting a contractor } \\
\text { by using a novel method for } \\
\text { multiple attribute } \\
\text { analysis: weighted } \\
\text { aggregated sum product } \\
\text { assessment with grey } \\
\text { values (WASPAS-G). }\end{array}$ & $\begin{array}{l}\text { Zavadskas, E. K; Turskis, Z; } \\
\text { Antucheviciene, J. }\end{array}$ & 54 & 10.8 & 3 & Article & 2015 & $\begin{array}{l}\text { Automation \& Control Systems; } \\
\text { Operations Research \& Management Science. }\end{array}$ \\
\hline 2 & $\begin{array}{l}\text { Artificial bee colony } \\
\text { (ABC) algorithm for } \\
\text { constrained optimization } \\
\text { improved with genetic } \\
\text { operators. }\end{array}$ & $\begin{array}{l}\text { Bacanin, N; } \\
\text { Tuba, M. }\end{array}$ & 50 & 6.25 & 2 & Article & 2012 & $\begin{array}{l}\text { Automation \& Control Systems; } \\
\text { Operations Research \& Management Science. }\end{array}$ \\
\hline 3 & $\begin{array}{l}\text { Multi-criteria } \\
\text { assessment model of } \\
\text { technologies. }\end{array}$ & $\begin{array}{l}\text { Zavadskas, E. K; Turskis, Z; } \\
\text { Volvaciovas, R; Kildiene, S. }\end{array}$ & 42 & 6.00 & 4 & Article & 2013 & $\begin{array}{l}\text { Automation \& Control Systems; } \\
\text { Operations Research \& Management Science. }\end{array}$ \\
\hline 4 & $\begin{array}{l}\text { A state of the art on } \\
\text { supply planning and } \\
\text { inventory control under } \\
\text { lead time uncertainty. }\end{array}$ & $\begin{array}{l}\text { Dolgui, A; } \\
\text { Ben A. O; Hnaien, F; } \\
\text { Louly, M. A. O. }\end{array}$ & 35 & 5.00 & 4 & Article & 2013 & $\begin{array}{l}\text { Automation \& Control Systems; } \\
\text { Operations Research \& Management Science. }\end{array}$ \\
\hline 5 & $\begin{array}{l}\text { optimization using } \\
\text { genetic algorithms for } \\
\text { multi-objective flexible } \\
\text { JSSP. }\end{array}$ & $\begin{array}{l}\text { Nicoara, E. S; Filip, F. G; } \\
\text { Paraschiv, N. }\end{array}$ & 33 & 3.67 & 3 & Article & 2011 & $\begin{array}{l}\text { Automation \& Control Systems; } \\
\text { Operations Research \& Management Science. }\end{array}$ \\
\hline 6 & $\begin{array}{l}\text { Adjusted fireworks } \\
\text { algorithm applied to } \\
\text { retinal image } \\
\text { registration. }\end{array}$ & Tuba, E; Tuba, M; Dolicanin, E. & 31 & 10.33 & 3 & Article & 2017 & $\begin{array}{l}\text { Automation \& Control Systems; } \\
\text { Operations Research \& Management Science. }\end{array}$ \\
\hline
\end{tabular}

All of the 6 most influential documents are articles and their research areas cover Automation \& Control Systems and Operations Research \& Management Science. The 6 articles are results of cooperation among authors, and only 1 of them was written by 2 authors while the other 5 of 
the 6 articles were written by 3 or 4 authors.

\subsection{The productive and influential countries/regions and institutions}

In this subsection, the countries/regions and institutions that mostly contribute to the journal from the perspective of productivity and influence respectively are analyzed. The indicators such as P, C, AC and H-index are exhibited.

\section{The most productive and the most influential countries/regions}

To analyze the productivity of countries/regions, the top 6 most productive countries/regions with publications not less than 20 and their annual publications are shown in Figure 2.

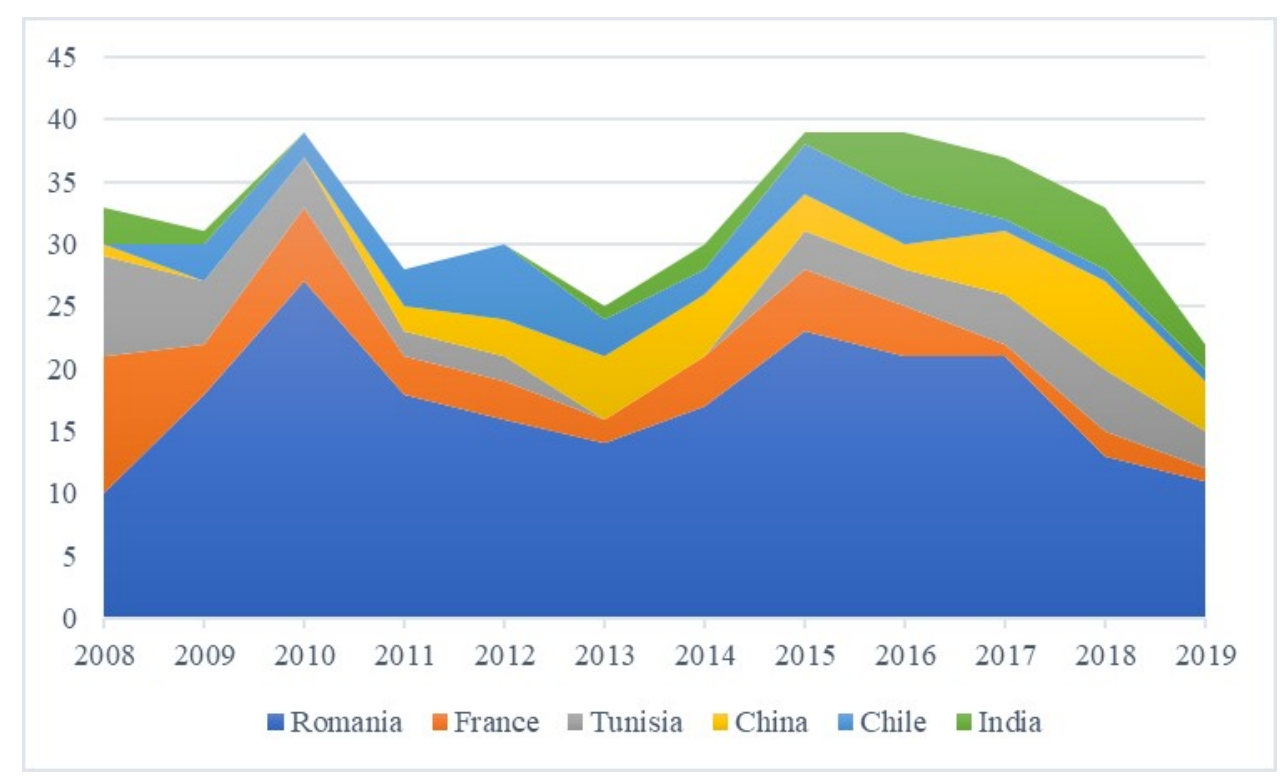

* As of November 1, 2019.

Figure 2: The annual publications of top 10 productive countries/regions from 2008 to 2019*.

The top 6 productive countries/regions are Romania (209), France (46), Tunisia (39), China (37), Chile (30) and India (25) in a strict order. The number of the total publications of the 6 countries/regions reached the highest value (39) in 2010, 2015 and 2016. Romania published more than 20 documents in the journal in 2010, 2015, 2016, and 2017 and it is the most productive country among the 6 countries/regions per year except for in 2008. In this year, France published 11 documents in the journal while the publication of Romania is 10 . As the second productive country, the publication of France is more than 10 documents only in 2008, and it published just 1 to 6 documents in the journal per year from 2009 to 2019. Chile had its first 3 publications in the journal way back in 2009, and has continued to publish at least one document in the journal until 2019. Some countries/regions published no documents in the journal only occasionally. The third productive country Tunisia published no documents in SIC in 2013 and 2014, and published at least 2 documents in the journal in other years. China published only 1 article in the journal in the first 3 years, while it published frequently in $S I C$ in the last 10 years. India published nothing in the journal during the period from 2010 to 2012.

To analyze the influence of countries/regions, the indicators are used to describe the citation structures of top 7 most cited publications which are cited not less than 100 times, as listed in Table 5 . 
Table 5: The top 7 influential countries/regions in SIC from 2008 to 2019*.

\begin{tabular}{cccccccccccc}
\hline Rank & Country/Regions & $\mathbf{P}$ & $\mathbf{C}$ & $\mathbf{A C}$ & $\mathbf{2 5 0}$ & $\mathbf{3 0}$ & $\geq \mathbf{2 0}$ & $\geq \mathbf{1 0}$ & $\mathbf{\geq}$ & $\geq \mathbf{1}$ & H-index \\
\hline 1 & Romania & $\mathbf{2 0 9}$ & $\mathbf{6 8 2}$ & 3.26 & 0 & 1 & 3 & $\mathbf{1 5}$ & $\mathbf{4 5}$ & $\mathbf{1 6 3}$ & $\mathbf{1 0}$ \\
2 & France & 46 & 209 & 4.54 & 0 & 1 & 2 & 6 & 14 & 38 & 8 \\
3 & Lithuania & 14 & 198 & $\mathbf{1 4 . 1 4}$ & $\mathbf{1}$ & $\mathbf{2}$ & 3 & 6 & 10 & 11 & 8 \\
4 & Serbia & 17 & 183 & $\mathbf{1 0 . 7 6}$ & $\mathbf{1}$ & $\mathbf{2}$ & $\mathbf{4}$ & 7 & 7 & 14 & 7 \\
5 & Chile & 30 & 133 & 4.43 & 0 & 0 & 2 & 3 & 8 & 26 & 5 \\
6 & Tunisia & 39 & 112 & 2.87 & 0 & 0 & 0 & 3 & 9 & 27 & 7 \\
7 & China & 37 & 107 & 2.89 & 0 & 0 & 0 & 3 & 8 & 25 & 5 \\
\hline
\end{tabular}

* As of November 1, 2019.

The most productive country Romania is also the most influential one with 682 citations and the highest value of H-index 10. Lithuania and Serbia are the only two countries with the value of $\mathrm{AC}$ over 10, which means their publications in the journal are cited more than 10 on average. They are also the only 2 countries with 1 of their publications in the journal cited not less than 50 times, and the 2 countries published less than 20 documents in the journal while obtained more than 180 citations. Although Lithuania published just 14 documents in SIC, it is the third influential country with the highest value of AC 14.14. As 1 of the top 6 productive country, India was not included for its publications in the journal are cited just 39 times in total. It is reasonable to infer that the number of citations have no any direct connection with the number of publications. In other words, a high number of publications does not always involve a high citation score.

\section{The most productive and the most influential institutions}

Table 6 lists the top 10 productive institutions whose number of publications exceeds 15 . The relative indicators are also listed in order to illustrate their productivity and influence.

Table 6: The top 10 productive institutions from 2008 to 2019*.

\begin{tabular}{|c|c|c|c|c|c|c|}
\hline Rank & Institutions & Countries/Regions & $\mathbf{P}$ & $\mathrm{C}$ & $\mathrm{C} / \mathrm{P}$ & H-index \\
\hline 1 & National Institute for R\&D in Informatics - ICI & Romania & 56 & 222 & 3.96 & 7 \\
\hline 2 & University Politehnica of Bucharest & Romania & 33 & 102 & 3.09 & 6 \\
\hline 3 & Université Lille Nord de France (ComUE) & France & 29 & 117 & 4.03 & 6 \\
\hline 4 & Romanian Academy of Sciences & Romania & 27 & 148 & 5.48 & 7 \\
\hline 5 & Fondation I-SITE Université Lille Nord-Europe (ULNE) & France & 27 & 115 & 4.26 & 6 \\
\hline 6 & Université de Lille & France & 27 & 115 & 4.26 & 6 \\
\hline 7 & École Nationale d'Ingénieur de Tunis & Tunisia & 22 & 74 & 3.36 & 6 \\
\hline 8 & Université de Tunis El Manar & Tunisia & 21 & 71 & 3.52 & 6 \\
\hline 9 & École Centrale Lille & France & 19 & 62 & 3.26 & 5 \\
\hline 10 & Pontificia Universidad Católica de Valparaiso & Chile & 17 & 69 & 4.06 & 5 \\
\hline
\end{tabular}

* As of November 1, 2019.

From Table 6, it can be figured out that the National Institute for R\&D in Informatics ICI Bucharest is the leading productive institution, with a number of publications almost twice higher than that of the second productive institution - University Politehnica of Bucharest. 4 of 10 institutions are in France, 3 of 10 institutions are in Romania, and other 2 are in Tunisia. Pontificia Universidad Católica de Valparaiso is the only institution from Chile. The publications of the top 6 institutions are more than 25, while the publications of other 4 are around 20 .

In fact, there is no significant difference in the list of top 10 productive and cited institutions. Vilnius Gediminas Technical University (Lithuania) takes the place of École Centrale Lille 
(France) and is the top 2 cited institutions with $13 \mathrm{P}, 183 \mathrm{C}, 14.54 \mathrm{AC}$ and the value of H-index 8. The relative indicators: $\mathrm{P}, \mathrm{C}, \mathrm{AC}$ and $\mathrm{H}$-index, are used to illustrate the influence of the top 10 influential institutions in Figure 3.

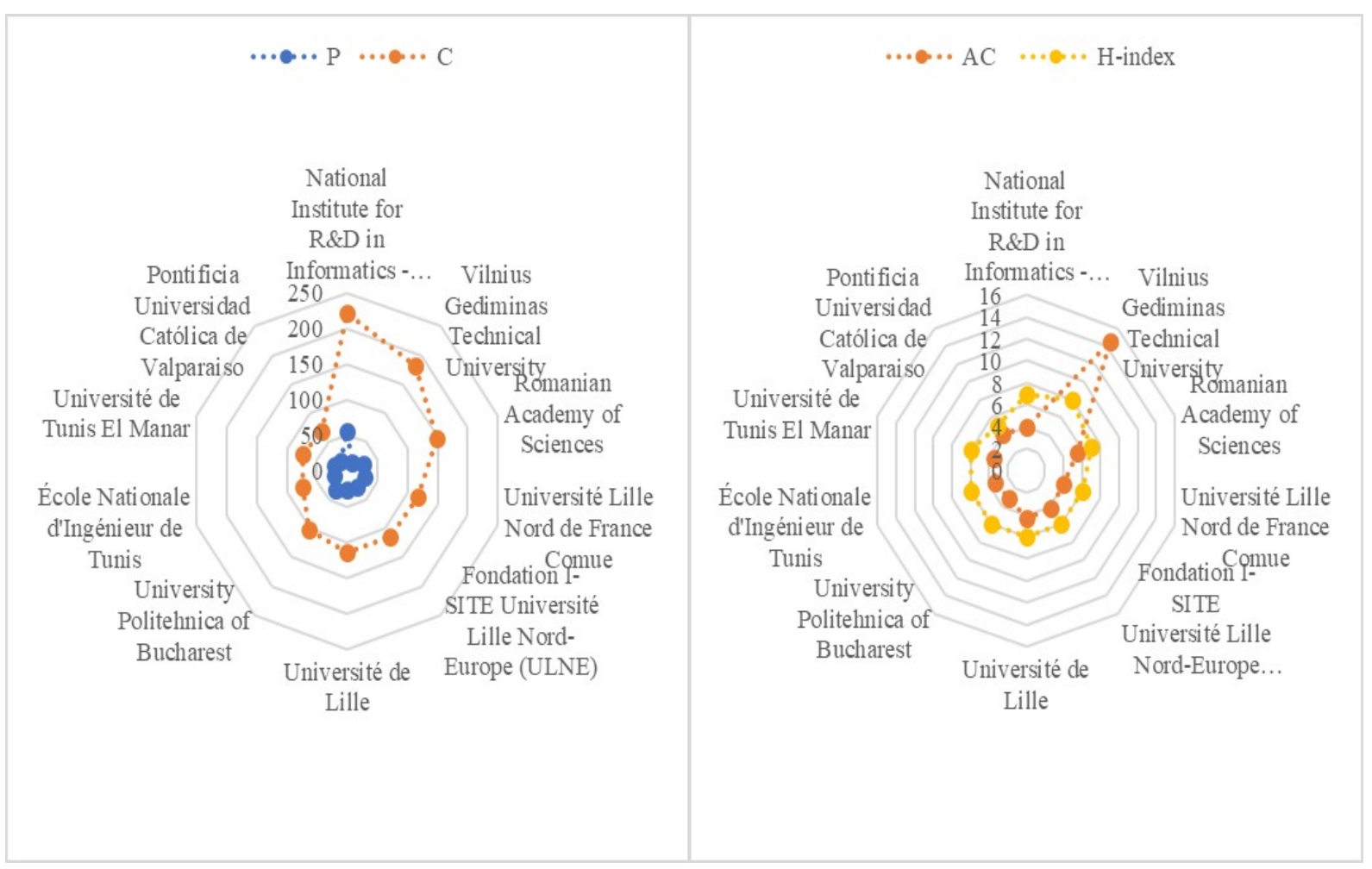

* As of November 1, 2019.

Figure 3: The radar map of top 10 productive institutions in terms of $\mathrm{P}, \mathrm{C}, \mathrm{AC}$ and $\mathrm{H}$-index from 2008 to $2019 *$.

The number of publications of the National Institute for R\&D in Informatics - ICI Bucharest (Romania) is distinctly higher than these of other institutions, while there are no obvious differences among other institutions. The number of citations is higher than the number of their publications, and the citations of the National Institute for R\&D in Informatics - ICI Bucharest (Romania) and Vilnius Gediminas Technical University (Lithuania) are one or half more than those of other institutions. There are no evident differences among the H-indices of these 10 institutions. The AC of Vilnius Gediminas Technical University (Lithuania) is 14.54, while the $\mathrm{AC}$ of other institutions are less than 6 .

\section{Science mapping analysis of $S I C$}

In order to intuitively display the structure of publications in SIC, science network maps have been developed by using the VoS viewer and CiteSpace regarding three different aspects: cocitation analysis, co-authorship analysis, and co-occurrence analysis. Parts of burst information are detected by CiteSpace and listed in Tables. The co-citation analysis of authors, references and journals, the co-authorship of authors, institutions, and countries/regions, co-occurrence of keywords and the corresponding burst detection of the 527 documents published in SIC are presented, respectively. 


\subsection{Co-citation analysis}

Co-citation was defined as the frequency with which two documents are cited together in the very beginning [22]. It was expanded into the co-citation analysis of journals and authors [26]. In the network of co-citation analysis, different nodes represent different references/journals/authors, and they are clustered by similarity and presented by a color. The size of the node represents the total number of citations with which the reference/journal/author is cited. The link between two nodes means that they are co-cited, and the size of the link represents the strength of their co-citation relationship. In the following, three types of co-citation analysis: references co-citation analysis, journals co-citation analysis, and authors co-citation analysis, are made, and all the network maps are established using VoS viewer.

Depending on the visualization tool VoS viewer, 8,335 cited authors are derived. In order to show them clearly, the minimum number of an author's citations is set at 10, and 52 authors meet the threshold. The cluster resolution is set at 0.5. The largest set of connected items consists of 49 authors, as shown in Figure 4.

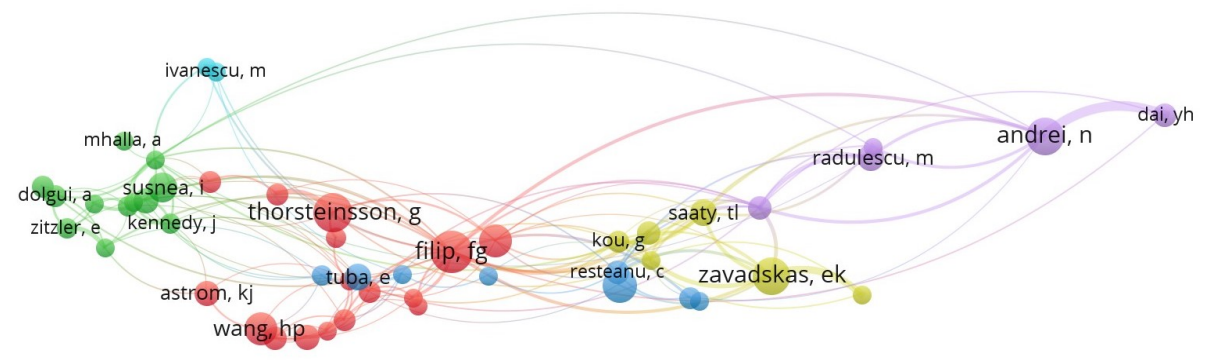

Figure 4: Authors co-citation network.

As Figure 4 illustrates, all of the 49 authors are classified into six clusters, which are represented by six different colors. The bigger the node is, the more the author is cited by documents published in SIC from 2008 to November 1, 2019. The most-cited author is Filip, F.G with 51 citations of his publications. The link shows the co-citation relationship between two authors. The width of the link is positively related to the strength of the relationship. The link between Andrei, N and Dai, Y. H is the widest, and the link strength is 93. This means that Andrei, N and Dai, Y. H are co-cited 93 times. Furthermore, the top 10 cited authors with the strongest citation bursts are listed in Table 7.

The cited author with the strongest citation bursts is Banciu, D from Romania. The strength of bursts is 3.9566 and the period of citation bursts is 2010-2014. The citation of Liouane, N from Tunisia burst in 2008 and 2009, and the citation bursts of other 9 authors occurred later than 2009. From 2010 to 2014, the citations of authors successively burst, and the citations of 3 authors burst in 2010. Only the citation of Zadeh, L. A from USA and Wang, H. P from China burst in last 3 and 4 years respectively, which means that the works of Zadeh, L. A and Wang, H. P have been taken into consideration and cited by many scholars in the last 3 or 5 years.

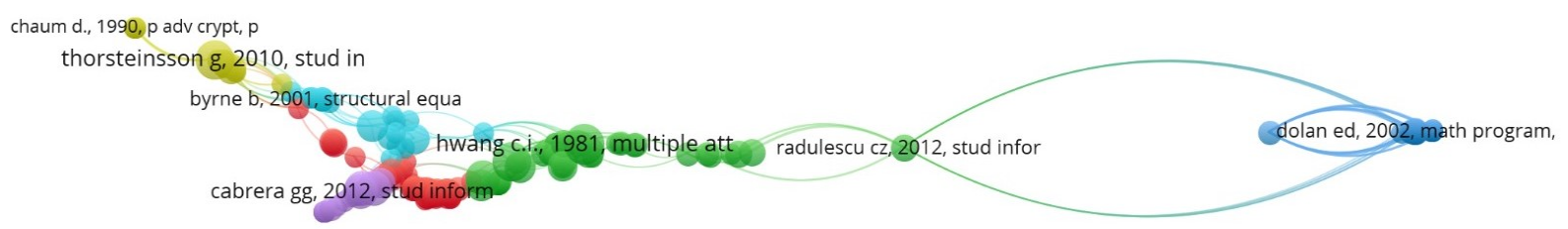

Figure 5: The references co-citation networks. 
Table 7: The top 10 cited authors with the strongest citation bursts from 2008 to 2019*.

\begin{tabular}{llllll}
\hline Rank & Cited Authors & Strength & Begin & End & 2008-2019 \\
\hline 1 & Banciu, D & 3.9566 & 2010 & 2014 & \\
2 & Suduc, A. M & 3.4812 & 2011 & 2013 & \\
3 & Zadeh, L. A & 3.4076 & 2017 & 2019 & \\
4 & Gabrera, G. G & 3.1207 & 2014 & 2015 & \\
5 & Susnea, I & 3.0751 & 2011 & 2014 & \\
6 & Thorsteinsson, G & 3.0739 & 2010 & 2013 & \\
7 & Liouane, N & 2.8432 & 2008 & 2009 & \\
8 & Peng, Y & 2.7815 & 2012 & 2013 & \\
9 & Page, T & 2.6353 & 2010 & 2012 & \\
10 & Wang, H. P & 2.5943 & 2016 & 2019 & \\
\hline
\end{tabular}

* As of November 1, 2019.

To visualize the references co-citation networks, the minimum number of citations of a reference is set at 3, and 209 of 10,810 references have met the threshold. Figure 5 illustrates the largest set of connected items which consists of 204 references. With the cluster resolutions set as 0.5 , there are six clusters differentiated by six colors. Two linked items are cited together at least once. Table 8 lists the top 1 reference with the strongest citation bursts from 2008 to 2019. The reference was published by Cabrera, G.G in 2012, and the citation of the reference bursts in 2014 and 2015. This means that the citations of this article in these 2 years are more numerous than those of the other years. Cabrera G.G et al. [4] proposed a hybrid algorithm which combines the Particle Swarm Optimization (PSO) algorithm and the Simulated Annealing (SA) algorithms to solve the Probabilistic Traveling Salesman Problem (PTSP).

Table 8: The top 1 reference with the strongest citation bursts from 2008 to 2019*.

\begin{tabular}{lllllll}
\hline Rank & Reference & Year & Strength & Begin & End & 2008-2019 \\
\hline \multirow{2}{*}{1} & Cabrera, G.G, 2012, & & & & & \\
& STUD INFORM CONTROL, & 2012 & 2.7439 & 2014 & 2015 & \\
& V21, P49 & & & & & \\
\hline
\end{tabular}

* As of November 1, 2019.

By setting the minimum number of citations of a journal at 20 and the resolution at 1.0, the journals co-citation network can be visualized in Figure 6. 46 of 6,286 journals are selected and SIC is the most cited journal (651 citations) followed by European Journal of Operational Research with 115 citations. Figure 6(a) shows the co-citation relationship between the 46 journals. The thicker the link is, the more the linked 2 journals are cited together. To make it clearer, the minimum strength of the link is set at 150 and the result can be seen in Figure 6(b). The existing links from Figure 6(b) show that the linked journals are co-cited not less than 150 times. Only 6 links meet the threshold, and the linked journals by the 6 links are illustrated in Table 9 .

For further studying of the cited journals, the CiteSpace has been applied in order to detect the citation bursts of them. The top 10 cited journals with the strongest citation bursts and the related information are listed in Table 10.

International Journal of Computers, Communications \& Control (IJCCC) is the journal with the strongest citation bursts 11.578, which is at least twice than those of others. Compared 


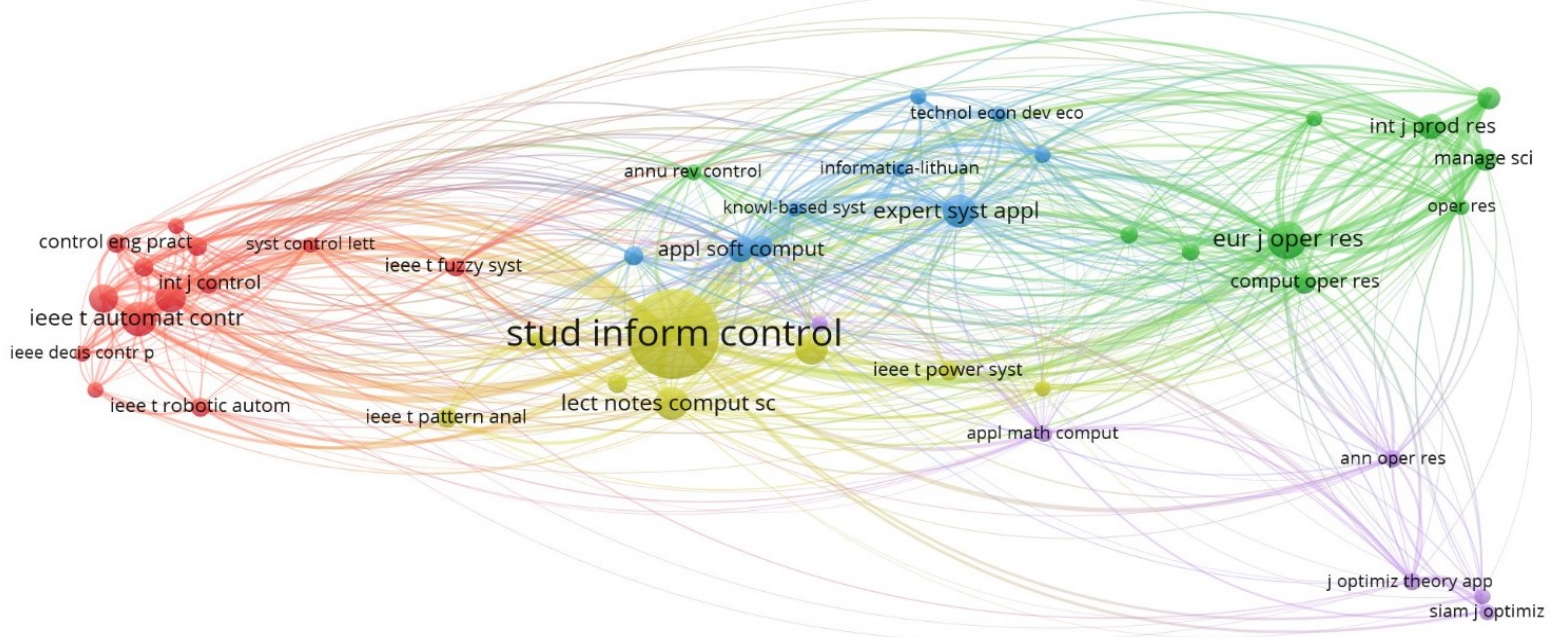

(a)

\footnotetext{
siam joptimiz
j optimiz theory app
}

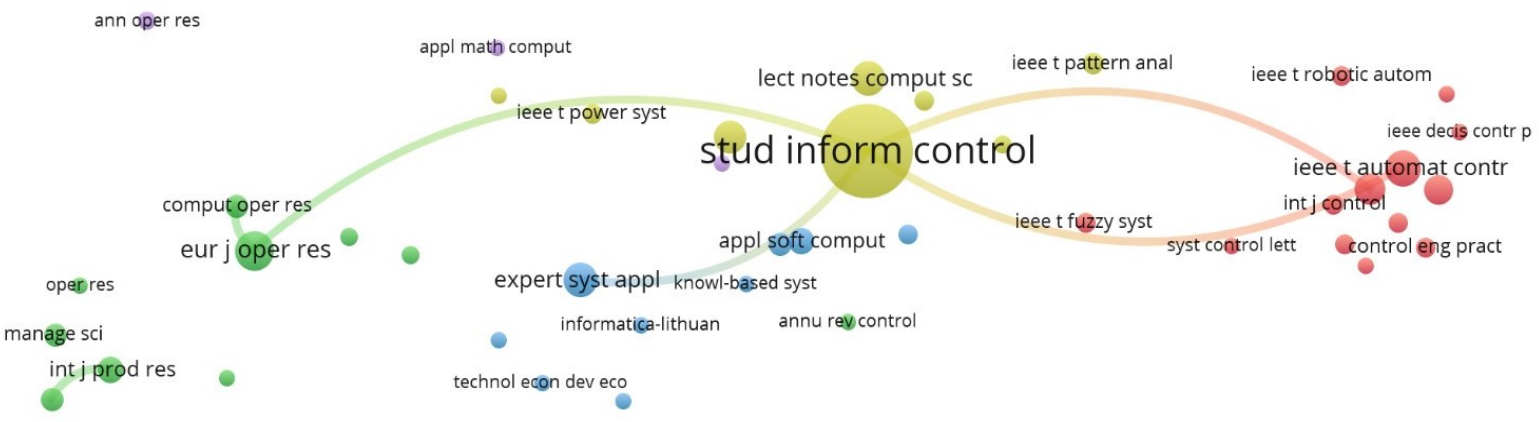

(b)

Figure 6: The journals co-citation network.

to other 2 journals whose bursts lasted for four years from 2009 to 2012, IJCCC is cited more than them. The citation bursts of most journals began in 2009, 2011 or 2013 and lasted for 2-4 years. The journals ISA Transactions is more cited than before, because its citation bursts occurred in the last 4 years.

\subsection{Co-authorship network}

Co-authorship reflects the collaborative relationship between authors/institutions/countries/regions that have published documents in the journal. In the following, the cooperation relationship is analyzed from the perspective of authors (microcosmic scale), institutions (middle scale) and countries/regions (macroscopic scale). The VoS viewer is applied in order to create the network maps and the CiteSpace in order to detect the citation bursts information.

It can be found that 1,147 authors published at least 1 document in SIC. In Figure 7, the largest set of connected items consists of 76 authors and their co-authorship networks are shown. With the clustering resolution set at $0.5,11$ clusters are derived and represented by 11 colors. The size of the node reflects the number of publications of the author, and the strength of the 
Table 9: The 6 couples of journals with strongest co-citation strength from2008 to 2019*.

\begin{tabular}{ccll}
\hline Rank & Link strength & Journal 1 & Journal 2 \\
\hline 1 & 172 & International Journal of Production Research & International Journal of Production Economics \\
2 & 165 & Computers \& Operations Research & European Journal of Operational Research \\
3 & 160 & Studies in Informatics and Control & IEEE Transactions on Automatic Control \\
4 & 155 & Studies in Informatics and Control & Expert System with Applications \\
5 & 153 & Studies in Informatics and Control & Automatica \\
6 & 150 & Studies in Informatics and Control & European Journal of Operational Research \\
\hline
\end{tabular}

* As of November 1, 2019.

Table 10: The top 10 cited journals with the strongest citation bursts from 2008 to 2019*.

\begin{tabular}{clcccl}
\hline Rank & Cited Journals & Strength & Begin & End & 2008-2019 \\
\hline \multirow{2}{*}{1} & International Journal of Computers & 11.578 & 2009 & 2012 & \\
& Communications \& Control & & & & \\
2 & European Journal of Operational Research & 4.6737 & 2011 & 2015 & \\
3 & Operations Research & 4.4687 & 2013 & 2016 & \\
4 & Computers in Industry & 4.2578 & 2011 & 2014 & \\
5 & Mathematical Programming & 3.9211 & 2008 & 2009 & \\
6 & Communications of the ACM & 3.9011 & 2009 & 2012 & \\
7 & IEEE Transactions on Neural Networks & 3.8133 & 2009 & 2012 & \\
8 & Journal of the Operational Research Society & 3.7977 & 2013 & 2015 & \\
9 & Journal of Intelligent Manufacturing & 3.7971 & 2011 & 2013 & \\
\hline & ISA Transactions & 3.7841 & 2016 & 2019 & \\
\hline
\end{tabular}

* As of November 1, 2019.

link represents the frequency of cooperation. The linked authors are cooperators and they finish at least 1 document with each other. In each cluster, almost every author has cooperated with the most productive author. By setting the minimum strength of link at 4, the Figure $7(\mathrm{~b})$ is derived. The strongest cooperation relationship is between Wang, H. P and Tian, Y, they have written 10 documents in cooperation. Wang, H. P and Christov, N have published 4 documents together, and they represent the second strongest cooperative relationship.

To analyze the co-authorship of the institutions, the VoS viewer has been employed to map the co-authorship networks. The minimum number of documents of an institution is set at 5 , and 32 of 457 institutions meet the threshold. Among all the 32 institutions, 17 are part of the largest connected network as shown in Figure 8 (with the clustering resolution set at 0.5).

17 institutions are grouped into 4 clusters which are marked in red, yellow, green and blue, and Figure 8 shows the cooperation relationship between them. The National Institute for R\&D in Informatics, ICI Bucharest and the University Politehnica of Bucharest are the two most productive institutions of them. The top 6 groups with the strongest cooperation are listed in Table 11. The National Institute for R\&D in Informatics maintains a strong cooperation with many other institutions.

The co-authorship network of countries/regions is shown in Figure 9. It is the largest linked network consisting of 54 countries/regions (there are 60 countries/regions in total) obtained by applying the VoS viewer.

International cooperation relationships among 54 countries/regions are exhibited in Figure 9. Romania, France, China and Tunisia are the four most productive countries. Table 12 lists 


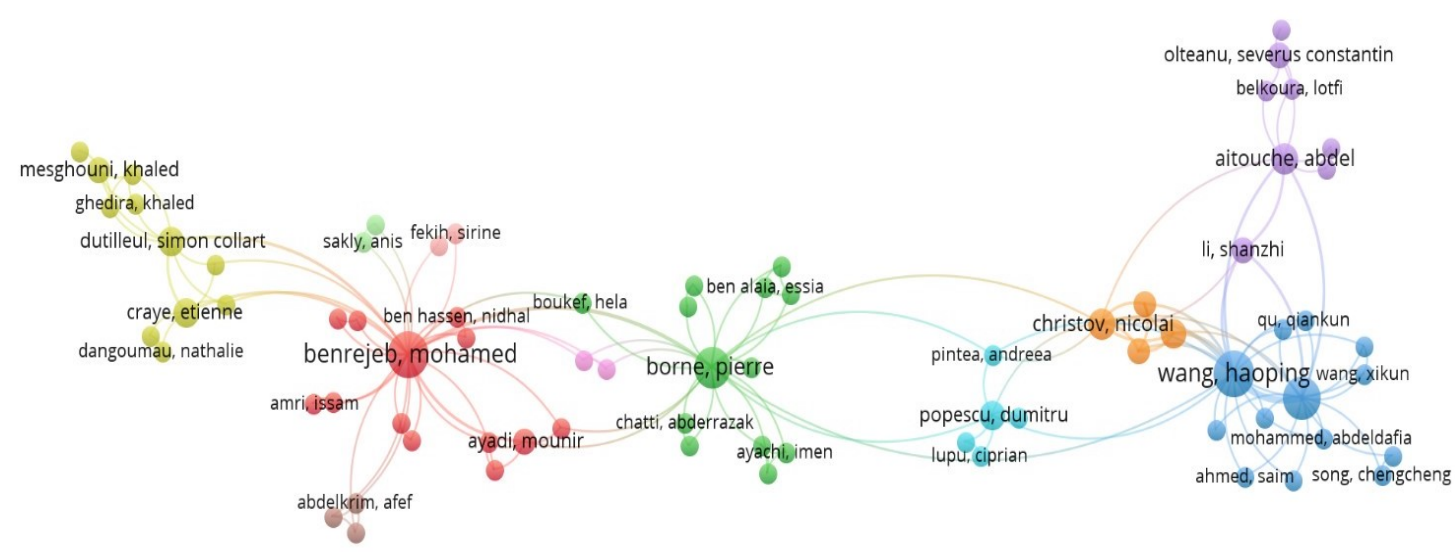

(a)

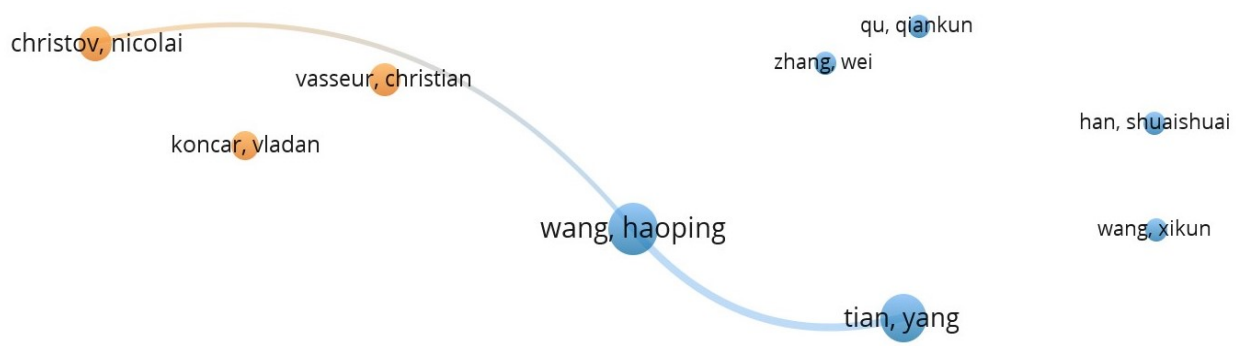

(b)

Figure 7: Co-authorship networks of authors.

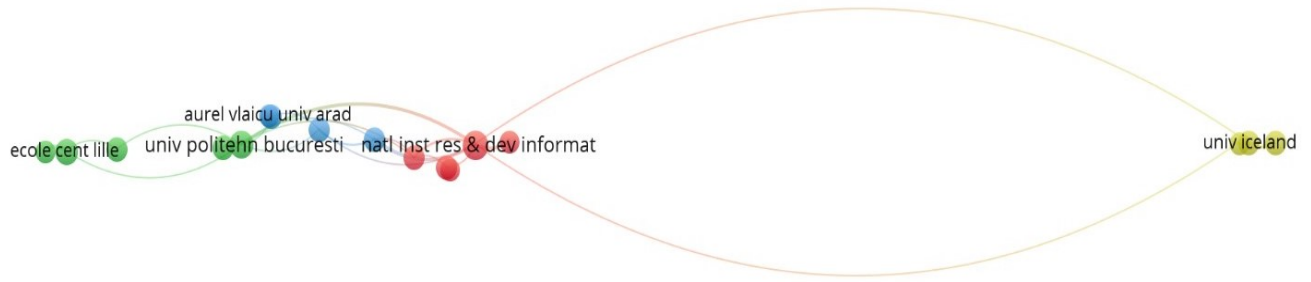

Figure 8: Co-authorship network of institutions.

the main international cooperation information of the top 6 most productive countries/regions.

The links represent the number of cooperators, and total link strength represents the number of international cooperative publications. Cooperation strength is the percentage of total link strength from the number of documents. The main cooperators of the 6 countries/regions and their link strength are listed, and the link strength represents the number of cooperative documents. Romania is the most productive (209 documents) country in the past 12 years and owns the most collaborative countries/regions. However, the total link strength of Romania (31) is not the highest, and the cooperation strength (14.83\%) is the lowest. France has published 46 documents in SIC since 2008, and $76.09 \%$ of these research works were written with authors from other 10 countries/regions. As the country with the highest cooperation strength (76.09\%), France establishes a strong international collaborative relationship. The collaborative strength between France and Tunisia is the strongest, and they have cooperated for 17 times. In the last 12 years, the authors from Tunisia have written documents with authors from France, Lithuania and Saudi Arabia. Indian authors prefer to cooperate with the authors who come from Romania, England, France and Oman. 
Table 11: The top 6 groups with the strongest cooperation from 2008 to 2019*.

\begin{tabular}{ccll}
\hline Rank & Link strength & Institutions 1 & Institutions 2 \\
\hline 1 & 7 & Spiru Haret University & University of Iceland \\
2 & 6 & École Centrale Lille & Ecole Nationale d'Ingénieur de Tunis \\
3 & 5 & Bucharest University of Economic Studies & National Institute for R\&D in Informatics - ICI \\
4 & 5 & CASA ACAD Romane & National Institute for R\&D in Informatics - ICI \\
5 & 4 & University Politehnica of Bucharest & National Institute for R\&D in Informatics - ICI \\
6 & 4 & Loughborough University & University of Iceland \\
\hline
\end{tabular}

* As of November 1, 2019.

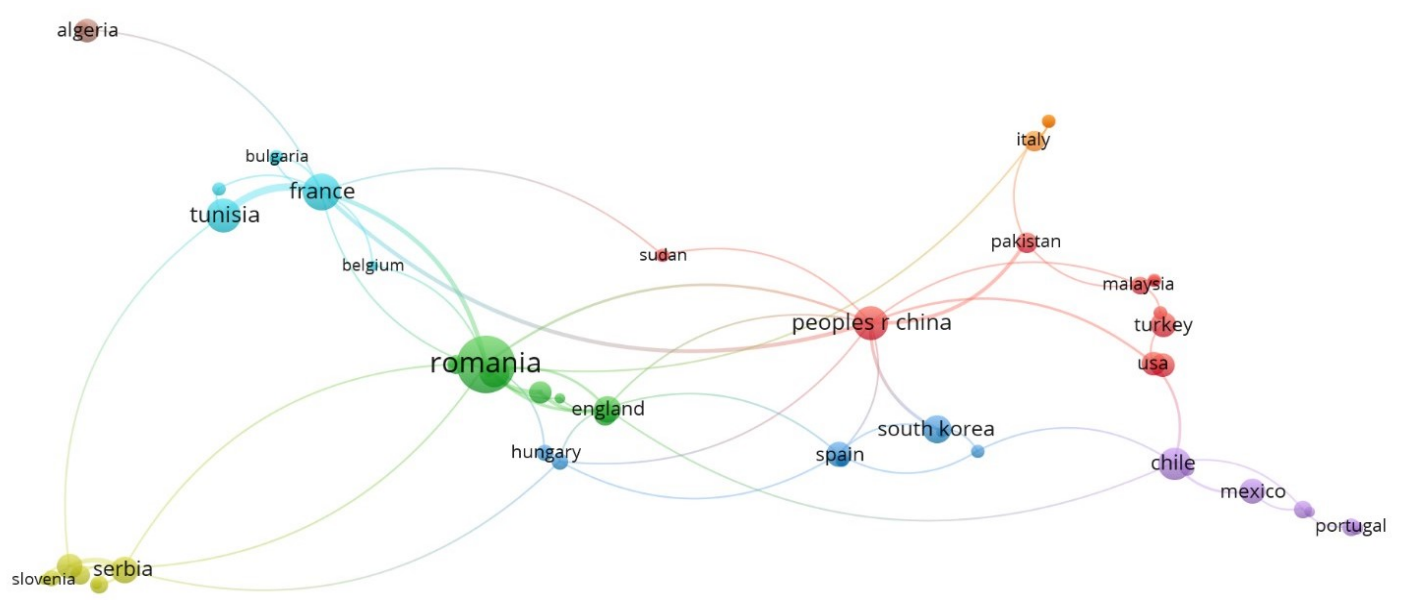

Figure 9: Co-authorship networks of countries/regions.

Next, CiteSpace is used to detect the citation bursts of authors, institutions, and countries/regions. Table 13 lists the top 1 author, the top 4 institutions and the top 5 countries/regions with the strongest citation burst from 2008 to 2019.

Tian, $\mathrm{Y}$ is the only one author with citation bursts over the past 12 years, and the citation bursts began in 2014 and lasted until 2019. The documents published by Tian Y in SIC have been cited more often in the last 6 years than in the first 6 years starting 2008. The documents of École Centrale de Lille has been cited more often in the preceding 4 years, while the documents of Vilnius Gediminas Technical University have gained a lot of attentions recently. University Politehnica of Bucharest has the highest strength of citation bursts (6.2612) from 2014 to 2017. The citation bursts of Tunisia and England occurred in 2008, and lasted for 2 or 3 years respectively. From 2011 to 2014, Spain had the highest strength of citation bursts (4.8054). The citation bursts of documents from Turkey have continued to 2019 from 2017.

\subsection{Co-occurrence analysis}

As a quantitative analysis method, co-occurrence analysis is useful to support the knowledge services and knowledge mining. The keywords show the research fields and the underlying trends of the publications. Thus, the keyword co-occurrence analysis is a good way to reveal the hot topics and research trends of the journal. The following research is based on 2,988 keywords detected by employing the CiteSpace.

Figure 10 shows the largest connected co-occurrence network and classification map of the keywords. The two linked keywords appear together in not less than 1 document. The top 7 most frequently used keywords are labeled. The bigger the node is, the higher the occurrence is. The network is divided into 6 clusters and the smaller the cluster ID is, the more components 
Table 12: The international cooperation of the top 6 most productive countries/regions from 2008 to $2019 *$.

\begin{tabular}{|c|c|c|c|c|c|c|c|}
\hline \multirow{2}{*}{ Rank } & \multirow{2}{*}{ Countries/Regions } & \multirow{2}{*}{ Documents } & \multirow{2}{*}{ Links } & \multirow{2}{*}{$\begin{array}{c}\text { Total link } \\
\text { strength }\end{array}$} & \multirow{2}{*}{$\begin{array}{c}\text { Cooperation } \\
\text { strength }\end{array}$} & \multicolumn{2}{|c|}{ Main cooperators } \\
\hline & & & & & & Countries/Regions & Link strength \\
\hline \multirow{4}{*}{1} & \multirow{4}{*}{ Romania } & \multirow{4}{*}{209} & \multirow{4}{*}{14} & \multirow{4}{*}{31} & \multirow{4}{*}{$14.83 \%$} & Iceland & 7 \\
\hline & & & & & & France & 6 \\
\hline & & & & & & India & 3 \\
\hline & & & & & & England & 3 \\
\hline \multirow{3}{*}{2} & \multirow{4}{*}{ France } & \multirow{4}{*}{46} & \multirow{4}{*}{10} & \multirow{4}{*}{35} & \multirow{4}{*}{$76.09 \%$} & Tunisia & 17 \\
\hline & & & & & & Romania & 6 \\
\hline & & & & & & China & 5 \\
\hline \multirow{3}{*}{3} & & & & & & France & 17 \\
\hline & \multirow[t]{2}{*}{ Tunisia } & \multirow[t]{2}{*}{39} & \multirow[t]{2}{*}{3} & \multirow[t]{2}{*}{19} & \multirow[t]{2}{*}{$48.72 \%$} & Lithuania & 1 \\
\hline & & & & & & Saudi Arabia & 1 \\
\hline \multirow{4}{*}{4} & \multirow{4}{*}{ China } & \multirow{4}{*}{37} & \multirow{4}{*}{10} & \multirow{4}{*}{21} & \multirow{4}{*}{$56.76 \%$} & France & 5 \\
\hline & & & & & & Pakistan & 4 \\
\hline & & & & & & South Korea & 3 \\
\hline & & & & & & USA & 2 \\
\hline \multirow[t]{2}{*}{5} & \multirow[t]{2}{*}{ Chile } & \multirow[t]{2}{*}{30} & 6 & 9 & $30.00 \%$ & Peru & 2 \\
\hline & & & & & & Mexico & 2 \\
\hline & & & & & & Romania & 3 \\
\hline 6 & India & 25 & 4 & 7 & $2800 \%$ & England & 2 \\
\hline 0 & India & 25 & 4 & $\gamma$ & $28.00 \%$ & France & 1 \\
\hline & & & & & & Oman & 1 \\
\hline
\end{tabular}

* As of November 1, 2019.

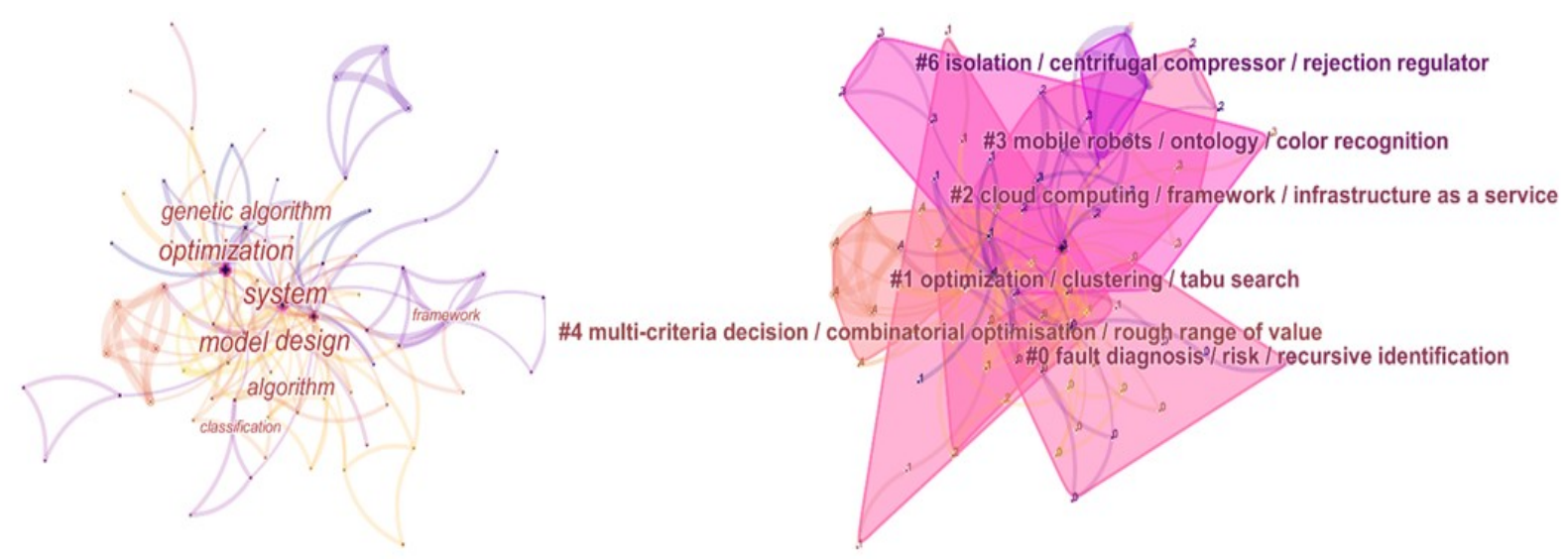

Figure 10: The keyword co-occurrence network and classification map.

the cluster has. The cluster is labeled with indexing terms and three algorithms: latent semantic index (LSI), log-likelihood ratio (LLR) and mutual information (MI) in sequence.

To analyze the hotspots and the underlying trends of the journal, the CiteSpace is applied in order to detect the top 5 keywords with the strongest citation bursts and to map the timeline view of keywords.

The main attention is paid to the keywords 'system', 'model', and 'design' which have frequently appeared in the journal during 2010-2011, 2012-2015, and 2012-2013 respectively, and 'model' is the keyword with the strongest citation bursts. In the last 4 years, the keyword 'algorithm' has gained much attention, and the research concerning this keyword has been prevalent. The keyword 'mobile robot' was paid much attention during 2012-2014. From Figure 11, it can be observed that most keywords of the publications are a combination of these three words. SIC not only focuses on the research of algorithms, models and system designs, but also pays attention to the application of these technologies and combination with other theories. Especially, they are combined with decision-making techniques, Internet, supply chain and energy. 
Table 13: The top 1 author, 4 institutions and 5 countries/regions with the strongest citation bursts from 2008 to $2019^{*}$.

\begin{tabular}{cccccc}
\hline Rank & Authors & Strength & Begin & End & 2008-2019 \\
\hline 1 & Tian, Y & 4.0459 & 2014 & 2019 & \\
\hline Rank & Institutions & Strength & Begin & End & 2008-2019 \\
\hline 1 & University Politehnica of Bucharest & $\mathbf{6 . 2 6 1 2}$ & 2014 & 2017 & \\
2 & École Centrale de Lille & 4.4988 & 2008 & 2011 & \\
3 & Petroleum-Gas University & 3.0844 & 2014 & 2016 & \\
4 & Vilnius Gediminas Technical University & 3.0109 & 2015 & 2019 & \\
\hline Rank & Countries & Strength & Begin & End & 2008-2019 \\
\hline 1 & Spain & 4.8054 & 2011 & 2014 & \\
2 & England & 4.0777 & 2008 & 2010 & \\
3 & Turkey & 3.5189 & 2017 & 2019 & - \\
4 & Tunisia & 3.4792 & 2008 & 2009 & \\
5 & USA & 2.9427 & 2009 & 2012 & \\
\hline
\end{tabular}

* As of November 1, 2019.

Table 14: The top 5 keywords with the strongest citation bursts from 2008 to 2019*.

\begin{tabular}{cccccc}
\hline Rank & Keywords & Strength & Begin & End & 2008-2019 \\
\hline 1 & Model & 4.5285 & 2012 & 2015 & \\
2 & Design & 3.3160 & 2012 & 2013 & \\
3 & System & 3.0302 & 2010 & 2011 & \\
4 & Algorithm & 2.9440 & 2016 & 2019 & \\
5 & Mobile Robot & 2.6314 & 2012 & 2014 & \\
\hline
\end{tabular}

* As of November 1, 2019.

\section{Conclusions}

The bibliometric analysis of the journal SIC is illustrated in this paper. The productivity and influence of authors, countries/regions, and institutions that have published documents in $S I C$, and the citations of the most cited documents is analyzed. The productivity and influence are reflected in terms of publications and citations, but also the H-index and other statistic information are used. A comprehensive performance analysis of the documents published in SIC between 2008-2019 is presented and illustrated. For an intuitionistic exhibition of the publications in SIC, science maps of the documents published in SIC from 2008 to 2019 have been developed, by using the visualization tools VoS viewer and CiteSpace. Co-citation analysis, co-authorship network and co-occurrence analysis are represented in visualization. Based on the above analysis, some conclusions are summarized as follows.

(1) SIC has had a more important influence in the area of IT in the last 10 years, and has gained more consideration and attention. Authors and institutions from Romania contribute most publications to the journal and gain most citations, while the average influence of their publications is not the highest. There is no doubt that Romania is one of the most productive and influential country in $S I C$, followed by France, Tunisia, China, Chile and India, respectively.

(2) The source of the references is extensive, as there are 8,335 cited authors and 6,286 


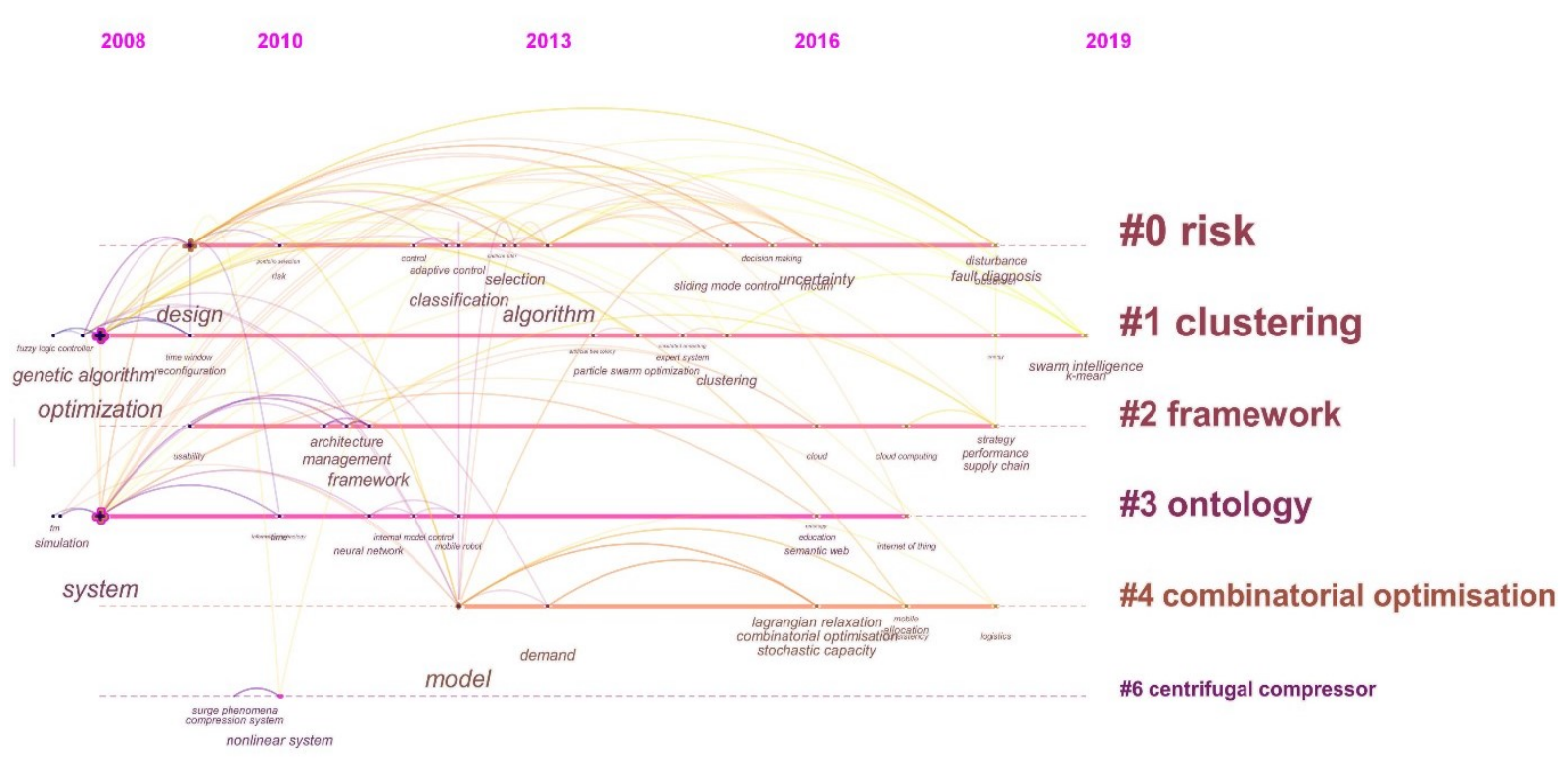

*As of November 1, 2019

Figure 11: The timeline view of keywords in SIC from 2009 to 2019*.

cited journals. SIC has the strongest co-citation relationship with other journals as the only one reference with the strongest citation bursts was published in SIC in 2012 by Cabrera, G.G.

(3) International cooperation relationship is not strong enough in this journal. Only $14.83 \%$ of the publications from Romania are collaborative documents, while Romania is the most productive country of SIC. On the contrary, $76.09 \%$ of the publications from France were written in international cooperation, 17 out of 46 in collaboration with authors from Tunisia. This is the strongest international collaboration relationship in SIC.

(4) The journal focuses mainly on IT and innovations in the relative technologies and applications. The research areas are getting wider, especially for the applications linked with other research directions.

Overall, this paper provides an objective and intuitionistic view of SIC by employing bibliometric analysis. It provides scholars a scientific way to understand the trends and the hot topics published in this journal. It might be of particular interest to researchers and professionals in the field of IT with its diverse applications. Last but not least, the relevant and reliable assessment data provided by this study may be beneficial to the authors, readers and editors of this well-established scientific quarterly.

\section{Bibliography}

[1] Aria, M.; Cuccurullo, C. (2017). Bibliometrix: An R-tool for comprehensive science mapping analysis, Journal of Informetrics, 11(4), 959-975, 2017.

[2] Braam, R.R. (1991). Mapping of science: foci of intellectual interest in scientific literature, DSWO Press, University of Leiden, 1991.

[3] Braun, T. (2005). Handbook of quantitative science and technology research: The use of publication and patent statistics in studies of S\&T systems, Scientometrics, 63(1), 185-188, 2005. 
[4] Cabrera, G.; Roncagliolo, S.; Riquelme, J.P.; Cubillos, C.; Soto, R. (2012). A hybrid particle swarm optimization-simulated annealing algorithm for the probabilistic travelling salesman problem, Studies in Informatics and Control, DOI: 10.24846/v21i1y201206, 21(1), 49-58, 2012.

[5] Cancino, C.A.; Merigó, J.M.; Coronado, F.C. (2017). A bibliometric analysis of leading universities in innovation research, Journal of Innovation \& Knowledge, 2(2), 106-124, 2017.

[6] Chen, C. (2006). CiteSpace II: Detecting and visualizing emerging trends and transient patterns in scientific literature, Journal of the American Society for information Science and Technology, 57(3), 359-377, 2006.

[7] Cobo, M.J.; López-Herrera, A.G.; Herrera-Viedma, E.; Herrera, F. (2011). Science mapping software tools: Review, analysis, and cooperative study among tools Journal of the American Society for Information Science and Technology, 62(7), 1382-1402, 2011.

[8] Cobo, M.J.; Martínez, M.A.; Gutiérrez-Salcedo, M.; Fujita, H.; Herrera-Viedma, E. (2015). 25 years at Knowledge-Based Systems: A bibliometric analysis, Knowledge-Based Systems, 80, 3-13, 2015.

[9] Costas, R.; Bordons, M. (2007). The h-index: Advantages, limitations and its relation with other bibliometric indicators at the micro level, Journal of informetrics, 1(3), 193-203, 2007.

[10] Coupé, T. (2003). Revealed performances: Worldwide rankings of economists and economics departments, 1990-2000, Journal of the European Economic Association, 1(6), 1309-1345, 2003.

[11] Diodato, V.P.; Gellatly, P. (2013). Dictionary of bibliometrics, Routledge, 2013.

[12] Dumitrache, I. (2018). The contribution of the Romanian automation to the development of civilization, In Filip F. G(ed.), Information Science and Technology in Romania (in Romanian), Editura Academiei Romane, Bucharest, 294-351, 2018. 294-351, 2018.

[13] Fagerberg, J.; Fosaas, M.; Sapprasert, K. (2012). Innovation: Exploring the knowledge base, Research Policy, 41(7), 1132-1153, 2012.

[14] Filip, F.G.; Suduc, A.M.; Bîzoi, M. (2014). DSS in numbers, Technological and Economic Development of Economy, 20(1), 154-164, 2014.

[15] Laengle, S.; Merigó, J.M.; Miranda, J.; Słowí Nski, R.; Bomze, I.; Borgonovo, E.; Dyson, R.G.; Oliveira, J.F.; Teunter, R. (2017). Forty years of the European Journal of Operational Research: A bibliometric overview, European Journal of Operational Research, 262(3), 803$816,2017$.

[16] Landström, H.; Harirchi, G.; Aström, F. (2012). Entrepreneurship: Exploring the knowledge base, Research Policy, 41(7), 1154-1181, 2012.

[17] Luor, T.; Lu, H.P.; Yu, H.; Chang, K. (2014). Trends in and contributions to entrepreneurship research: A broad review of literature from 1996 to June 2012, Scientometrics, 99(2), 353-369, 2014.

[18] Merigó, J.M.; Blanco-Mesa, F.; Gil-Lafuente, A.M.; Yager, R.R. (2017). Thirty years of the International Journal of Intelligent Systems: A bibliometric review, International Journal of Intelligent Systems, 32(5), 526-554, 2017. 
[19] Mongeon, P.; Paul-Hus, A. (2016). The journal coverage of Web of Science and Scopus: a comparative analysis, Scientometrics, 106(1), 213-228, 2016.

[20] Noyons, E.C.; Moed, H.F.; Luwel, M. (1999). Combining mapping and citation analysis for evaluative bibliometric purposes: A bibliometric study, Journal of the American society for Information Science, 50(2), 115-131, 1999.

[21] Podsakoff, P.M.; MacKenzie, S.B.; Podsakoff, N.P.; Bachrach, D.G. (2008). Scholarly influence in the field of management: A bibliometric analysis of the determinants of university and author impact in the management literature in the past quarter century, Journal of Management, 34(4), 641-720, 2008.

[22] Small, H. (1973). Co-citation in the scientific literature: A new measure of the relationship between two documents, Journal of the American Society for information Science, 24(4), 265-269, 1973.

[23] Tuba, M.; Tuba, E. (2019). Generative Adversarial Optimization (GOA) for acute lymphocytic leukemia detection, Studies in Informatics and Control, 28(3), 245-254, 2019.

[24] Van Eck, N.; Waltman, L. (2009). Software survey: VOSviewer, a computer program for bibliometric mapping, Scientometrics, 84(2), 523-538, 2009.

[25] Wang, X.X.; Xu, Z.S.; Dzitac, I. (2019). Bibliometric Analysis on Research Trends of International Journal of Computers Communications \& Control, International Journal of Computers Communications \& Control, 14(5), 711-732, 2019.

[26] White, H.D.; Griffith, B.C. (1981). Author cocitation: A literature measure of intellectual structure, Journal of the American Society for information Science, 32(3), 163-171, 1981.

[27] Yu, D.J.; Xu Z.S.; Saparauskas J. (2019). The evolution of Technological and Economic Development of Economy: A bibliometric analysis, Technological and Economic Development of Economy, 25(3), 369-385, 2019.

[28] Yu, D.J.; Xu, Z.S.; Kao, Y.S.; Lin, C.T. (2018). The structure and citation landscape of IEEE Transactions on Fuzzy Systems (1994-2015), IEEE Transactions on Fuzzy Systems, 26(2), 430-442, 2018.

[29] Yu, D.J.; Xu, Z.S.; Pedrycz, W.; Wang, W.R. (2017). Information sciences 1968-2016: A retrospective analysis with text mining and bibliometric, Information Sciences, 418, 619$634,2017$.

[30] Zavadskas, E.K.; Stević, R.; Turskis, Z.; Tomašević, M. (2019). A novel extended EDAS in Minkowski Space (EDAS-M) method for evaluating autonomous vehicles, Studies in Informatics and Control, 28(3), 255-264, 2019.

[31] Zhou, W.; Xu Z.S.; Zavadskas, E.K. (2019). A bibliometric overview of International Journal of Strategic Property Management between 2008 and 2019, International Journal of Strategic Property Management, 23(6), 366-377, 2019. 